\title{
CONCEPÇÕES DE CIÊNCIAS DA EDUCAÇÃO EM ALGUNS AUTORES COLOMBIANOS
}

\author{
LAMAR, Adolfo Ramos ${ }^{1}$ - Universidade Regional de Blumenau - FURB \\ TIEDT, Jacson ${ }^{2}$ - Universidade Regional de Blumenau - FURB
}

\begin{abstract}
RESUMO:
No Brasil, diversos grupos de pesquisa têm interesse em se aprofundar na Educação em outros países latino-americanos. A presente pesquisa forma parte do grupo "Filosofia e Educação" (Educogitans), Universidade Regional de Blumenau (FURB), Blumenau, Santa Catarina, Brasil, que tem interesse em se aprofundar na problemática epistemológica educacional latino-americana. Colômbia é um dos países latino-americanos com uma expressiva produção sobre a referida problemática. Assim, o objetivo da presente pesquisa é identificar e analisar algumas concepções de cientificidade no pensamento epistemológico da educação na Colômbia. Visa aprofundar as concepções de Ciências da Educação por parte de autores colombianos. Também se aprofundará em como consideram o objeto da epistemologia e sua importância para a América Latina. Os dados foram coletados mediante os levantamentos bibliográficos e documentais e interpretados no contexto das perspectivas da epistemologia da Educação na América Latina.
\end{abstract}

Palavras-Chave: Ciências da Educação - Pedagogia - Colômbia.

\section{ABSTRACT:}

In Brazil, several research groups have an interest in further education in other Latin American countries. This research forms part of the group "Philosophy and Education" (Educogitans), Regional University of Blumenau (FURB), Blumenau, Santa Catarina, Brazil, which has interest in deepening Latin American educational epistemological problems. Colombia is one of Latin America with a significant production on that issue. The objective of this research is to identify and analyze some of the scientific concepts of epistemological thought of education in Colombia. The research aims to deepen the concepts of Education by Colombian authors. Also consider how to deepen the object of epistemology and its importance for Latin America. Data were collected

\footnotetext{
${ }^{1}$ Doutor em Educação e Mestre em Política Científica e Tecnológica pela Universidade Estadual de Campinas (UNICAMP), Pós doutor em Filosofia da Educação pela USP e Licenciado em Filosofia pela Universidade de Havana, Cuba Professor do PPGEFURB e Membro do Grupo de Pesquisa Filosofia e Educação (Educogitans). E-mail: ajemabra@yahoo.com.br

${ }^{2}$ Mestre em Educação pela Universidade Regional de Blumenau (FURB), Brasil. Membro do Grupo de Pesquisa Filosofia e Educação (Educogitans) do Programa de Pós-graduação em Educação Stricto Sensu da Universidade Regional de Blumenau (PPGE/FURB), Blumenau, Santa Catarina. E-mail: tchegre@hotmail.com
} 
through the bibliographic and documentary and interpreted in the context of the perspectives of epistemology of Education in Latin America.

KeYWORDS: Science Education - Pedagogy - Colombia.

\section{INTRODUÇÃO}

No Brasil, existem diversos grupos de pesquisa que se preocupam com o pensamento latino americano e tem, entre seus objetivos, saber como a questão de estatuto de epistemologia tem se manifestado em outros grupos latino-americanos. O Grupo de Pesquisa Educogitans, da Universidade Regional de Blumenau - FURB, Blumenau, Santa Catarina, tem como um de seus objetivos abordar as tendências epistemológicas na Educação Brasileira e de alguns países latino-americanos. Colômbia é um dos países latino americanos pesquisados, pois há um expressivo trabalho sobre a Epistemologia da Educação realizado por estudiosos como Olga Lúcia Zuluaga Garces, Rômulo Gallego Badillo,Alfonso Tamayo Valencia, Mário Diaz Villa, Rafael Rios Beltrán, Alberto Martinez Boon e Alexander Yarsa de Los Rios.

Partindo do exposto, o presente artigo objetiva abordar algumas concepções de ciências da educação, no pensamento epistemológico da educação na Colômbia. O artigo foi feito mediante a revisão bibliográfica e a discussão com integrantes do grupo Educogitans da FURB e do Grupo Paideia da Faculdade de Educação da Universidade Estadual de Campinas (UNICAMP). Assim, as informações foram coletadas em publicações periódicas latino-americanas e em alguns livros disponíveis sobre o assunto.

\section{A Formação das Ciências da Educação na Colômbia}

Desde o começo do século $X X$, até mais ou menos a década de 1950, a educação colombiana se caracterizou por tentar se apropriar dos saberes modernos que guiavam as sociedades desenvolvidas, ou seja, formar um Educador que reunia a ciência e a técnica de sua transmissão de conhecimentos. A partir de então, surgiram as reformas na educação pública, em especial para a formação de professores e de funcionários de escolas públicas.

\section{Segundo Gallego Badillo (2010, p.05)}

Hay dos momentos significativos en el país. El primero, cuando las autoridades educativas, desde las condiciones anteriores, deciden que la mayoria de ciudadanos accedan a la cultura científica; un eixo histórico que se inicio en Occidente en el siglo XIX. El segundo, cuando toman la decision de que esa enculturacion debe se asumida por profisionales que han de ser formados para tal cometido, en instituciones acadêmicas estabelecidas y conformadas para responder por esta intencionalidad.

Ao se olhar para a infância, se afirmava que o campo das ações pedagógicas e da educação pública na Colômbia havia sido orientado pela Pedagogia Ativa. Porém, entre 1926-1954, com adoção do discurso das Ciências da Educação na Colômbia, surge então a Escola de Ciências da Educação, em 1926, na Universidade de Antioquia e posteriormente das Faculdades de Ciências da Educação em Bogotá e Tunja, em 1933 e 1934, respectivamente. Com o surgimento daquelas instituições, podemos considerar 
as ciências da educação como uma nova prática de saber e formação de professores e funcionários da educação pública.

Em uma primeira exploração documental, indícios permitem ver que as ciências da educação tendiam a converter-se em saber que organizava o discurso nas instituições formadoras de docentes; as Escolas "Normales" (já existentes) e as Faculdades de Ciências da Educação (por criar-se). Havia também a presença da "Escuela Nueva" e o discurso das comunidades religiosas sobre a Pedagogia (los Lasallistas y Salesianos entre otras). Naquele contexto é que as ciências da educação tiveram lugar de saber maior, tendo consequências metodológicas muito importantes, como objeto de pesquisa.

Tais consequências apontam para estabelecer um corte, um ponto novo, um foco de discursos e de práticas, reconduzidos pelas ciências da educação. Por exemplo, se dá um novo enfoque ao objeto da educação secundária, sem menosprezar a primária. As ciências humanas, que entram nos planos de estudos, e as ciências que rodeiam, de maneira mais imediata, a pedagogia. Significa também que os saberes das instituições educativas deveriam renovar-se à luz dos novos conhecimentos, que partiriam das Ciências da Educação.

Naquele momento, foram criadas as escolas de Ciências da Educação, na Universidade de Antioquia em 1926, a Faculdade de Ciências da Educação, na Universidade Nacional, em 1933, a Academia de Ciências da Educação, em 1933, a Faculdade de Ciências da Educação, em Tunja, em 1934, a Faculdade de Ciências da Educação para Señoritas, em Bogotá, em 1934, e a Faculdade de Ciências da Educação da Universidade de Antioquia, em 1954.

Há indícios de que Rafael Bernal Jimenez foi o primeiro reitor da Faculdade de
Ciências da Educação, em Bogotá. Ele havia sido representante do governo colombiano, na Suíça, durante vários momentos de sua vida educativa e política. Entre os anos 1928 e 1932, foi Secretário de Delegação Colombiana, na Suíça. O início dos trabalhos com as Ciências da Educação na Colômbia não chegaram por via da França, mas por via da Suíça, com as orientações do Instituto Jean Jacques Rousseau, ou Escola de Ciências da Educação, fundada em 1912, na Universidade de Genebra, no referido País.

As concepções elaboradas pela investigadora Olga Lucia Zuluaga permitem visualizar as Ciências da Educação colombianas em sua existência social e discursiva. Referimo-nos às noções de prática pedagógica, saber pedagógico, apropriação e noção de acontecimento de saber. designa:

Em sua opinião, a Prática pedagógica

1- Los modelos pedagógicos tanto teóricos como prácticos utilizados en los diferentes niveles de ensenanza.

2- Una pluralidad de concptos pertencientes a campos heterogêneos de conocimiento retomados y aplicados por la Pedagogia.

3- Las formas de funcionamiento de los discursos en las instituciones educativas donde se realizan prácticas pedagógicas.

4- Las características sociales adquiridas por la práctica pedagógica en las instituciones educativas de una sociedad dada que asigna unas funciones a los sujetos de esa practica.

5- Las prácticas de enseñanza en diferentes espacios sociales, mediante elementos del saber pedagógico. ( ZULUAGA, 1999, p.147)

Essa noção permite tratar a Pedagogia como teoria e prática, como o que permite 
aos professores entrar em relação com o conhecimento. Nesta noção, se articulam três instâncias metodológicas: a instituição, o sujeito e o discurso. Com elas, a noção de prática pedagógica assume uma maior mobilidade analítica, circulando dinamicamente entre a interioridade e exterioridade dos discursos e saberes.

O olhar epistemológico sobre a produção científica consiste em situá-la no foco do questionamento e através deste viabilizar caminhos que possibilitem uma melhor reflexão e compreensão sobre o que se produz. Assim, a partir da epistemologia, a ciência e sua produção ganham novos contornos, distanciando-se da estagnação do conceito de verdade absoluta e buscando conceitos de verdade como processo.

Por processo de institucionalização de um saber se entende, "[...] el conjunto de reglas que para la institucion, el sujeto y el discurso de un saber pedagógico, delimitan la práctica del mismo saber en una formación social dada. Se dice "práctica"de un saber para ubicar que la región del análisis no separa mecanismos del poder y acontecimientos del saber" (ZULUAGA, 1999, p.149)

As considerações acerca da prática pedagógica e do saber pedagógico na sociedade colombiana requerem instrumentos conceituais, provenientes de diferentes campos: a epistemologia, a história do saber e a história da educação.

A área da epistemologia é compreendida como uma atividade filosófica que assume como tarefa analisar o estatuto do discurso científico, explicitando seus fundamentos. Para Japiassu (1988, p.24), a epistemologia é definida por três funções básicas: situar o lugar do conhecimento científico dentro do domínio do saber; estabelecer os limites do conhecimento científico e interrogar sobre as possibilidades deste conhe- cimento.

Segundo Yarsa de los Rios (2005, p.293), a epistemologia explica o funcionamento das ciências, a construção de seus conceitos, instrumentos, práticas, objetos de saber, as relações políticas e sociais. É uma ferramenta para a objetivação e relativização das verdades e se faz presente nos discursos com estatuto de cientificidade e veracidade. p.25)

Ainda em Bunge (apud LAMAR, 1998,

A Epistemologia ou filosofia da ciência é o ramo da filosofia que estuda a pesquisa científica e seu produto, o conhecimento científico. Mera foIha da árvore da filosofia meio século atrás, a Epistemologia é hoje um ramo importante dela [...] A Epistemologia transformou-se, em suma, numa área importante da filosofia, tanto conceptual como profissionalizante [...]. Até meio século atrás a Epistemologia não era mais que um capítulo da teoria do conhecimento ou gnosiologia.

O discurso epistemológico encontra, na filosofia, seus princípios e, na ciência, seu objeto. Tem como finalidade não só resolver o problema das relações entre filosofia e ciência, mas servir de ponto de encontro entre elas.

Segundo Sanchez Gamboa (2007, p.27) afirma:

A epistemologia é uma palavra que designa a filosofia das ciências, porém com um sentido mais preciso. Não é uma teoria geral do saber ou teoria do conhecimento que seria objeto da gnosiologia, nem é um estudo dos métodos científicos que seria objeto da metodologia, mas é 
parte da filosofia que se ocupa especialmente do estudo crítico da ciência em seu detalhamento prático, isto é, da ciência como produto e como processo;nesse sentido, é um estudo fundamentalmente a posteriori.

Para Diaz Villa (1993, p.31);

El campo pedagógico es un campo estructurado y estructurante de prácticas pedagógicas. En que consisten estas prácticas? Con el término práctica pedagógica, generalmente nos referimos a los procedimientos, estratégias y acciones que prescriben la comunicacion, el acesso al conocimiento, el ejercicio del pensamiento, de la vision, de las posiciones, oposiciones y disposiciones y relaciones sociales de los sujetos en la escuela.

O surgimento, tanto institucional, como discursivo, das Ciências da Educação, na Colômbia, significou um novo acontecimento para a formação de professores de educação secundária. Elas se institucionalizaram em Instituições como a Universidade de Antioquia, em 1926, com o nome de Escola de Ciências da Educação; nas faculdades de Ciências da Educação, em Bogotá, em 19331934, Tunja, em 1934, e Medellín, em 1954.

Em 1926, pela primeira vez na Colômbia, surge uma instituição relacionada com as Ciências da Educação. Referimo-nos à Escola de Ciências da Educação da Universidade de Antioquia, que foi apresentada na Assembleia de Antioquia, pelo deputado Tomás Cavidad Restrepo, para preparar os professores para a educação secundária. Com esta proposta, Cavidad Restrepo pretendia ir contra as posições que consideravam o ensino como um assunto onde só não basta saber a matéria para ensinar.
Para Cavidad Restrepo (apud RIOS BELTRAN, 2004, p.76) "Todo el que enseña debe procurar educar y necesita, por lo tanto, posser algunos conocimientos de psicologia y de los métodos más apropiados para cumplir su misión: los que manejan la juventud no deben ignorar la esencia de la nobre porción que esta ante su cátedra."

A Escola de Ciências da Educação foi criada como faculdade universitária, pelo Governo de Antioquia, mediante a lei 19 de 7 de abril de 1926. A lei determinava as seguintes matérias de estudo: Psicologia, Fisiologia, Pedagogia, História da Educação, Legislação Escolar, Sociologia, Higiene Escolar, Metodologia, Ética e um curso superior de educação cívica. Os alunos que tinham sido aprovados nos cursos da Escola de Ciências da Educação recebiam um certificado de competência pedagógica e seriam preferidos para lecionar nos colégios de educação secundária e para ocupar os altos postos de instrução pública. Porém, pela falta de alunos e por tensões surgidas no interior da Universidade da Antioquia o curso fecha em 1932.

Fracassada a ideia de formar profissionais nas Ciências da Educação, em Antioquia, Rafael Bernal Jimenez apresentou uma proposta ao Ministério da Educação, em 1932, para criar a Faculdade de Ciências da Educação, em Bogotá. Aquela proposta se concretizou com o Decreto 1990 de 1933, mediante o qual se dava a existência institucional das Ciências da Educação, na Universidade Pedagógica Nacional da Colômbia.

A Faculdade de Ciências da Educação compreendia os seguintes estudos: Pedagogia, Ciências Históricas e Geográficas, Ciências Físico-Químicas, Biologia, Filosofia, Letras, Matemáticas e Idiomas. Com esses saberes, a faculdade buscava formar um professor que reunia a ciência e técnica de sua transmissão de conhecimentos. Não 
queria uma Ciência sem Pedagogia, nem uma Pedagogia sem Ciência. Essa faculdade outorgava títulos de licenciado em Ciências da Educação, com sua especificidade, e o título de doutor em Ciências da Educação. Os estudos de licenciatura eram outorgados depois de três anos letivos ordinários, com aprovação de todos os cursos regulamentados e de doutor, depois de ter praticado durante dois anos, como professor sob inspeção da Faculdade.

Por sua vez, a Faculdade de Ciências da Educação de Tunja foi fundada mediante o decreto 1939, de 5 de julho de 1934. Para esta Faculdade, se estabeleceu as seguintes especializações: Matemáticas e Física, Físico-Química, Idiomas Modernos, com a duração de quatro anos para estudos universitários.

Um ano mais tarde e com um contexto político de centralização e unificação na formação de professores da educação pública, as três faculdades de Ciências da Educação de Antioquia, Tunja e Bogotá foram unificadas em uma só, mediante o decreto 1917 de 25 de outubro de 1935. Porém, em menos de dois meses, o Congresso da Colômbia, mediante a lei 39 de 21 de fevereiro de 1936, determinou que a Faculdade de Educação, continuaria funcionando com o nome de Escola Normal Superior. Essa mudança na Faculdade Universitária gerou acaloradas discussões entre Diretores e Estudantes, contra as tendências centralistas do governo. Este argumentava que a mudança de nome e de dependência da Faculdade se deu para proteger a assegurar a formação do magistério e para solucionar seus problemas de ordem fiscal. Por outra parte, Diretores e Estudantes da desaparecida Faculdade de Bogotá argumentavam que aquela mudança dava "status" de Educação universitária na formação de professores.

A Faculdade de Ciências da Educação
"Escola normal Superior" funcionou somente entre os anos de 1936 a 1951. A partir de então, se divide a Escola em Escuela Normal Superior de Varones en Tunja y Escuela Normal Superior feminina en el Instituto Superior de Pedagogia em Bogotá. Anos mais tarde, estas duas instituições se converteriam em "Universidad Pedagogica y Tecnológica de Colômbia" e "Universidad Pedagogica Nacional". As "Ciências da Educação" são um acontecimento de saber compreensivo de tudo o que havia sobre o saber pedagógico colombiano, durante 0 período de 1926 a 1954. Escolas "Normales", saberes experimentais e sociais, Escuela Nueva, crítica aos métodos de ensino, o ensino primário, o ensino secundário, a infância e a adolescência, a pedagogia e os professores e outros foram pensados e institucionalizados como: "Ciencias de la Educación". Sem dúvida, pensar sobre a complexidade desses temas teve como consequência a dispersão do campo da pedagogia colombiana.

Para Rios Beltran (2004), as Ciências da Educação na Colômbia não foram um acontecimento isolado. Pelo contrário, sua institucionalidade nas Faculdades de Ciências em Bogotá, Tunja e Medellín, esteve relacionada com diferentes acontecimentos que funcionaram como antecedentes a sua criação e existência institucional ao saber pedagógico colombiano, durante a primeira década do século XX. Em primeiro lugar, encontramos as instituições médicas que se caracterizaram em ser as instituições que se apropriaram, pela primeira vez, do discurso da Escola Nova ou Pedagogia Ativa. Nelas, em especial na Faculdade de Medicina da Universidade Nacional da Colômbia, foi onde se iniciaram as críticas aos métodos de educação tradicional e onde se introduziram as primeiras noções de saberes experimentais baseadas nas técnicas e na ciência.

Em segundo lugar, a Lei 39 de 1903, 
também chamada de "Ley Uribe", foi como o ponto de partida de toda a reforma educativa, na primeira metade do século XX. Com esta Lei se começa a projetar a necessidade de fazer trocas, tomar novos rumos e orientações na empresa e na juventude colombiana. Desta maneira, introduziu novos saberes e métodos para a formação dos professores e as novas gerações, determinando, assim, a formação de um sujeito produtivo, útil, com iniciativa individual.

Em terceiro lugar, encontramos a criação, em 1914, do "Ginásio Moderno", em Bogotá. Esta instituição se caracterizou, no âmbito Nacional e latino americano, por sua primeira instituição que funcionou com os saberes experimentais próprios da Escola Nova, ou Pedagogia Ativa.

Em quarto lugar, temos a Escola Normal Central (1908 - 1935), a qual se caracterizou por ser a pioneira na adoção dos métodos modernos experimentais, em dar os primeiros esboços da pedagogia experimental e propor a Pedagogia de John Dewey na formação de professores na Colômbia.

E, finalmente, estão os cursos Suplementares de Especialização e de Informação Pedagógica, criados em 1926 e 1932, em Tunja e Bogotá, respectivamente. Estes cursos se dirigiram aos professores em exercício e se fundamentaram nos saberes experimentais.

As concepções epistemológicas sobre as ciências experimentais têm evoluído, juntamente com os conceitos metodológicos das Ciências experimentais. Assim, hoje se está falando de tais ciências, desde uma perspectiva cognoscitiva, uma ciência como atividade que se supõe mais adequada para o planejamento de educação, como investigação, e de aprendizagem, como processo. Reconhecida como atividade comunitária que tem consequências sociais, mantém seu caráter axiológico, dos quais os cientistas justificam a necessidade daquilo que produzem. E neste sentido, é de aceitação a ideia de que as ciências são construções sociais.

Com a criação da Escola de Ciências da Educação, em Antioquia (1926), as Faculdades de Ciências da Educação, em Bogotá (1933), Tunja (1934), Medellín (1954), podemos enumerar algumas mudanças que se concretizaram:

- As práticas de ensino começaram a transformar-se em práticas de observação pelo método de Pestalozzi, a partir do ensino de corte experimental. Em outros termos, com o surgimento das Ciências da Educação colombiana, os saberes e práticas pedagógicas começaram a transformar-se em um novo conceito epistemológico.

- A instituição das Ciências da Educação colombiana significou um novo olhar para a formação dos professores colombianos.

- Através da criação das Ciências da Educação, romperam-se muitos aspectos da formação de professores, acolhendo novos saberes e concepções de homem e sociedade.

- A concepção de professor "apóstolo", própria da pedagogia clássica, foi se transformando com a apropriação das ciências da educação que formava um professor moderno, conhecedor das leis científicas e psicológicas da infância e portador de um conhecimento histórico do aluno.

Em suma, as Ciências da Educação se dirigem em primeiro lugar ao professor, o sujeito do saber pedagógico. Porém, a institucionalização das Ciências da Educação não erradicou dos professores, de suas práticas pedagógicas de educação, sustentadas na memorização e repetição, nem muito menos se aplicaram imediatamente nas escolas primárias e secundárias, os métodos de experimentação. Foi um processo lento e, em 
algumas regiões da Colômbia, é um projeto ainda a se realizar.

\section{Segundo Rios Beltran ( 2004, p.81)}

Em 1926, a partir da criação da Universidade de Antioquia se considerava urgente adotar nas "Escuelas Normales" do Departamento de Antioquia de laboratórios de psicologia experimental. Além disso, formar o professor em conhecimentos dos problemas sociais tal e como se desenvolvia na "Escuela de Ciencias de la Educación.

Este momento institucional gerou algumas mesclas metodológicas e confusões aos professores e diretores de educação pública, pois se encontravam em meio de uma avalanche de enunciados, provenientes dos saberes experimentais, clássicos e sociais. Os programas de estudo ainda conservavam as concepções clássicas, ao lado das modernas de corte experimental. Assim, se pode ver no programa de estudos da Escola de Ciências da Educação. No primeiro ano, as três seções de estudo: Matemáticas, Línguas e Comércio se desenvolviam no primeiro semestre e o curso de psicologia racional. No segundo semestre, se desenvolvia o curso de psicologia experimental.

Na Colômbia, o objeto de educação secundária existia desde o final do período colonial, tal como hoje o conhecemos, e se originou em 1892 durante "La Regeneracion". Este segundo nível de educação estava nas práticas pedagógicas, sob a orientação de comunidades religiosas. Os saberes que circulavam eram orientados pela Igreja Católica, a qual era a instituição hegemônica dos saberes acerca do homem. Além disso, nas comunidades religiosas, os docentes chegavam ao nosso País: Jesuítas, La Sallistas, Maristas, entre outras. Estes tinham um discurso pedagógico sobre a educação secundária formado desde o século XVI. Em consequência, os professores da educação secundária geralmente eram religiosos. Aspecto normal na Colômbia, onde a metade da educação secundária estava nas mãos de Congregações Católicas.

Por outra parte, a educação secundária se dirigia somente aos filhos das elites e aos estudos clássicos, técnicos e literários. Todavia, não havia na Colômbia uma formação dirigida para formar professores de educação secundária nos saberes pedagógicos, ou seja, uma instituição que formara os "Professores dos Professores". Muitos dos professores de educação secundária vieram do setor primário, os quais em sua maioria não tinham nenhuma formação pedagógica científica.

Neste sentido, as reformas do magistério, durante as primeiras décadas do século $X X$, se dirigiram exclusivamente à educação primária. A educação secundária não era objeto de reformas em nível de formação de professores. Ela se dava no interior dos colégios, mediante as faculdades outorgadas pelo Decreto 1047 de 1912, para expedir o título de professor. p.81):

Ainda, segundo Rios Beltran (2004,

Nesse contexto, as Ciências da Educação se dirigiram ao objeto de educação secundária, não para criálo pela primeira vez na Colômbia, senão para dá-lo uma nova direção como espaço de formação específico dos professores de Colégios e "Escolas Normales". Assim entendeu, Rafael Bernal Lopez, primeiro Diretor da Faculdade das Ciências da Educação, quando pensava criar o que não existia, uma instituição para formar os professores para a educação secundária. 
As Faculdades de Ciências da Educação surgiram para reformar e transformar a educação secundária nos Colégios que se dedicavam a expedir, por encargo do Governo Nacional, títulos de professores, ou habilitações para ensinar e instruir em nível de educação secundária. Se as reformas da educação primária na Colômbia, no princípio do século XX, se dirigiram à infância, a institucionalização das Ciências da Educação se dirigiram à adolescência, como objeto privilegiado, porém, sem desprezar totalmente a infância. Em outras palavras, se a educação primária se dedicava a conhecer a criança, cujo único objeto de estudo e de intervenção era a "pediatria", por outro lado, a educação secundária, reformada como espaço de formação de professores desde as Ciências da Educação, amplia sua mirada de saberes que não intervém somente na infância, senão também tais como, a antropologia, a psicologia e a sociologia, entre outras disciplinas.

Ao falarmos de pedagogia, estamos num campo de conhecimento cruzado por diferentes perspectivas e de múltiplos interesses.

Segundo Tamayo (2007, p.66):

En Colômbia se reconece que es a partir de la década de los 80 cuando "florece el campo de la investigacion pedagógica" debido entre otros acontecimientos a la superacion del enfoque de la tecnologia educativa que la habia "enrarecido" AL subsumirla entre las ciências de la educacion y le habia asignado una existência subordinada, una conceptualizacion desrticulada, una atomizacion de su objeto y un caráter instrumental.

Os acontecimentos como o Movimento Pedagógico, as novas legislações educativas, as pesquisas de pós-graduação, as pu- blicações em educação e pedagogia, a consolidação dos Centros de Investigações e os Programas de Estudos Científicos em Educação e Pedagogia (Colciencias) permitem dispor de um profundo conhecimento a respeito do ensino, da instrução, da formação, da educação, da didática, da aprendizagem, que são advindos do conceito pedagogia.

Para Gallego Badillo (2004, p.7):

Lá investigacion em este campo didático posee una larga traayetoria. Señalense, en particular, los trabajos a cerca de las ideas epistemológicas, pedagógicas y didáticas procedidos por trabajos de mayor alcance, que dieron lugar as campo general identificado como " el pensamiento del professor". Estas concepciones, de conformidad con lo afirmado serian las histórico epistemológicas, las didáticas y pedagogicas, em especifica relacion con cada modelo cientifico.

Neste sentido, é imprescindível identificar e caracterizar a concepção de história da epistemologia geral e especifica. A histórica pode ser caracterizada pela ideia linear e cumulativa do pensamento e da atividade cientifica, em relação com a concepção de ciência que o professor tem elaborado. Epistemologia científica é no sentido de domínio da lógica interna da estrutura conceitual e metodológica de cada modelo científico.

Segundo Tamayo (2006, p.102):

La Reforma educativa que proponia el gobierno se fundamentaba en los principios de la psicologia conductista y reducia el maestro a ser un simple "administrador de currículo", pensado, organizado e impuesto por " los técnicos del ministério de educación" quienes obsesionados por el cuplimiento de "objetivos instruccionales", negaban la voz y el 


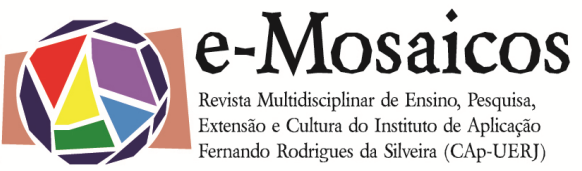

pensamiento a los maestros, reducian el processo de aprendizage al cumplimiento de objetivos "observables" predeterminados por la Tecnologia educativa y el disenõ instrucional (TEYDI) así como también centraban la enseñanza en la transmision fiel de contenidos.

Na Colômbia, os debates giram em
torno das reflexões históricoepistemológicas, porque, nem a pedagogia, nem as ciências da educação têm um método específico para a construção de um discurso científico. As análises, sob uma perspectiva histórica, apontam mais pesquisas sobre a pedagogia do que sobre as ciências da educação, isto porque a pedagogia é "/a disciplina que conceptualiza, aplica y experimenta los conocimientos referentes a la enseñanza de los saberes específicos, en diferentes culturas." (ZULUAGA, 1999, p.11).

Segundo Mockus (1994,p.57), em "Las Fronteras de la Escuela" faz uma relação entre o conhecimento escolar e ressalta a necessidade de construir alternativas didáticas para passar do conhecimento de sentido comum ao conhecimento científico, mediante estratégias comunicativas que permitam acesso à ciência e à formação do espírito científico.

\section{p.14)}

Para Alberto Martinez Boom (2003,

La expedición Pedagógica Nacional aborda el concepto de saber como algo muy importante para poder pensar la pedagogia más Allá de lãs concepciones que de Ella se tienen como ciência o como disciplina. De esta manera su relacion com la pedagogia es más cercana pues no la vê unicamente como una disciplina cinetífica sino como la totalidad de lãs prácticas en las cuales se produ- cen objetos de saber.

O que propõem Zuluaga e sua equipe de investigação," História de las Prácticas Pedagógicas em Colômbia" é uma história da pedagogia, não para situá-la em relação com a ciência, nem muito menos para delimitar e legitimar sua região de cientificidade. Trata-se de recuperá-la como uma nova prática discursiva, isto é, como saber (saber pedagógico) e como prática (prática pedagógica). É aqui que o "Grupo História de la Práctica Pedagógica en Colômbia"problematizou a história das condições de existência do professor no presente e do seu saber pedagógico. Estas questões impulsionaram uma história das práticas e os saberes que foram condições de possibilidade da existência do professor e da pedagogia. Nesta perspectiva, foram surgindo, na educação colombiana, os "Movimentos Pedagógicos" cujo interesse é elaborar uma reforma educacional e incorporar inovações pedagógicas e investigativas.

\section{CONCLUSÃo}

O histórico das tendências pedagógicas, que configuram a história da educação, é tema fundamental na formação de educadores de qualquer organização social e País, porque este histórico traz consigo a história do conhecimento, da ciência, da civilização.

A tarefa central, para enfrentar o desafio de preservar nossa identidade cultural, é investir constantemente na construção de uma pedagogia latino americana, aberta ao universal e destinada a fortalecer nossa capacidade de participação nos destinos da educação. Neste sentido, os esforços de apropriação dos desenvolvimentos internacionais sobre o pensar e o fazer educação devem estar subordinados aos elementos 
formadores de nossa identidade.

Mediante a problemática da cientificidade da educação entre alguns autores colombianos, foram apresentadas concepções referentes à educação, epistemologia, ciências da educação e pedagogia. Ao estabelecer as relações entre os temas citados é imprescindível fazer algumas observações.

O surgimento das ciências da educação rodeia, de maneira imediata, a pedagogia. Desta forma, as ciências da educação, em sua existência discursiva, referem-se às práticas pedagógicas. As considerações acerca da prática pedagógica e do saber pedagógico colombiano requer instrumentos conceituais provenientes da epistemologia. O surgimento, tanto institucional, como discursivo, das ciências da educação na Colômbia, significou um novo olhar para a Pedagogia.

Além disso, optar pela pedagogia como conhecimento é torná-la capaz de pensar em suas condições específicas na Colômbia. Isto significa que na Colômbia não se fala simplesmente em história da educação, leis e medidas educativas, mas de fato em uma história da pedagogia e da prática. Uma história da educação que ultrapassa o quadro formal, científica e institucional. Vista assim, a história da educação e da pedagogia não tem a ver apenas com história de legislação, fiscalização e recepções, mas também com a história de contextualizações, apropriações e aplicações do conhecimento.

Mais que uma história da educação, mais que uma história de ideias, mais que uma história teórica, mais que uma história de reformas e decretos para encaminhar e se tornar a história da prática pedagógica colombiana, com suas consequências teóricas e práticas. Isto significa ser capaz de fazer uma história crítica e efetiva de sua prática, de seu conhecimento e seus concei- tos. Significa historiar as condições em que são apresentados os conhecimentos pedagógicos e suas implicações no contexto educacional.

A atividade do pedagogo é refletir constantemente as práticas, as teorias e nutre seu pensamento das ciências da educação. Assim, as práticas de investigação dos pedagogos permitem compreender os impactos da desigualdade escolar e as políticas sociais da educação.

Do mesmo modo, a história da educação, e de seus sistemas de investigação, é uma fonte valiosa de conhecimentos que o pedagogo colombiano explora em seu favor. Conhecer as normas que regem a educação e o sistema em seu conjunto; as transformações da escola, as reformas escolares, os tipos de educação, a formação dos professores, sua transformação, os modelos de escola, tudo isso se converte em uma fonte de informação valiosa para o pedagogo.

Se a pedagogia é produtora de um saber e de um saber prático, não é ilusão dizer que no interior das ciências de educação haja uma relação harmônica. Desde suas origens, as ciências da educação pretendiam apoderar-se do saber da pedagogia.

Esta visão positivista da pedagogia é, desde a década de setenta do século passado, quando a Didática aparecia como um campo discursivo, sobre aprender e ensinar. Deste modo, se parte do princípio de que a educação é um elemento fundamental, sem o qual o ser humano não teria seu pleno desenvolvimento.

Esta característica sobressai quando se estabelece alguns elementos que permitem visualizar o desenvolvimento do pensamento, de tal forma, que o estudo da pedagogia não pode ser isolado de elementos como: espaço, as relações sociais, a educação, o sistema, o conhecimento, os 
saberes, a pessoa e suas relações com outras pessoas, a motivação, a ética, etc. Então, a pedagogia ocupa um lugar central nas ciências da educação, porque sabe interrogar o que as outras ciências fazem. O saber, o saber fazer, o saber ser, se aplica de um modo diferente como se aplica a didática, a sociologia ou a história. Por isso, a importância das ciências da educação consiste em ser um espaço institucional, um referente da cultura e um meio de saber.

\section{REFERÊNCIAS BIBLIOGRÁFICAS:}

GALLEGO BADILLO, Rômulo. "La Institucionalizacion de la actividad científica en Colombia". Revista Educacion y Educadores. vol13, no 3 (2010)

. "Un Concepto Epistemologico de Modelo para la Didática de las ciências experimentales". Revista eletrônica de Enseñanza de las Ciencias. vol. $3 \mathrm{n}^{0}$ 3, 2004.

JAPIASSU,H. Introdução ao Pensamento Epistemológico. Rio de Janeiro, Francisco Alves, 1988.

LAMAR, Adolfo Ramos. A pesquisa educacional e a concepção "kuhniana" da ciencia: o caso das teses de doutorado da FE/UNICAMP -Tese Doutorado. Orientador Prof. Dr.Sílvio Ancizar Sanchez Gamboa. Campinas, São Paulo, 1998.

MARTINEZ BOOM, A. Hacia um atlas de La pedagogia colombiana. Alternativas, IX, 2004.

MOCKUS. Antanas. Las Fronteras de la escuela. Ed. Magisterio. Bogotá,1994.

RIOS BELTRÁN, R. "Las Ciencias de la Educacion en Colombia: algunos elementos históricos sobre su apropiacion e intitucionalizacion 1926 - 1954"). Revista Memória
\& Sociedade. vol 08 no 12 - junio deciembre (2004) .

SANCHEZ GAMBOA, S. A. Pesquisa em Educação: métodos e epistemologias. Chapecó, Ed.Argos, 2007.

TAMAYO V, Alfonso.Tendencias de la Pedagogia en Colombia.latinoam.estud.educ. Monizales. 3, 65-76 enero-junio de 2007.

"El Movimiento Pedagógico en Colombia". Revista HISTEDBR. no 24, p.102-113, dez, 2006.

VILLA, Mario D . "El Campo intelectual de La Educacion en Colômbia". Textos Universitários. Universidade Del Valle, Cali, (1993).

YARZA de los Rios, Alexander. "Apuntes para uma epistemologia y uma pedagogia de educacion especial en Colombia". Revista de Pedagogia, Escuela de Educación, Univerdidad Central de Venezuela. Caracas, 2005, no 76, mayo-agosto, p.281305,2005.

ZULUAGA, Olga Lucia. Pedagogia e Historia. Editorial Universidad de Antioquia,Bogotá,(1999). 